\title{
AMICUS CURIAE COMO GARANTIDOR DO DEVIDO PROCESSO LEGAL.
}

\section{${ }^{1}$ Maria Cristina Zainaghi \\ ${ }^{2}$ Mônica Bonetti Couto}

\begin{abstract}
RESUMO
No presente estudo buscaremos analisar o instituto da Amicus Curiae no ordenamento brasileiro, debatendo sua inserção legislativa e o próprio desvirtuamento que vem se aplicando ao instituto Trataremos do histórico do instituto, com as divergências quanto a sua origem e, o início de sua inserção no ordenamento pátrio, bem como sua função no processo, tanto no aspecto original, como na releitura feita pelo legislador. Analisaremos, também, o princípio do devido processo legal, que será conceituado e explicado, buscando a correlação de ambos. Para esse estudo utilizaremos o método de revisão bibliográfica para obtermos o resultado pretendido.
\end{abstract}

Palavras-chave: Amicus curiae, Princípio, Devido processo legal

\section{AMICUS CURIAE COMO LA GARANTIA DEL PROCESO DEBIDO DE LA LEY}

\section{RESUMEN}

En el articulo analizaremos al instituto de las Amicus Curiae en la orden brasileña, discutiendo su inserción legislativa y desvirtuamento que se viene aplicando al instituto. Trataremos de la descripción del instituto, con las divergencias cuánto su origen y, su inserción en la orden nativa, tambien cuanto la función en el processo; el aspecto original, según lo en el releitura hecho para el legislador. Analisaremos, tambien, el principio del proceso debido de la ley, su concepto y valoracion, para entonces buscar la correlación de ambos. Para este articulo utilizaremos el método de revisión bibliográfica para conseguir el resultado previsto.

Keywords/Palabras-claves/Mots-clés: Amicus curiae, Principio, Debido processo legal

\footnotetext{
1 Doutora em Direito pela Pontifícia Universidade Católica - PUC/São Paulo, Brasil. Professora Titular da Universidade Nove de Julho - UNINOVE São Paulo, e Conferencista no Departamento de Cultura da Ordem dos Advogados do Brasil/SP. E-mail: criszai@uol.com.br

2 Doutora em Direito pela Pontifícia Universidade Católica - PUC São Paulo, Brasil. Pesquisadora e Professora do Programa de Mestrado em Direito pela Universidade Nove de Julho - UNINOVE, Brasil. E-mail: monicabonetticouto@yahoo.com.br
} 


\section{INTRODUÇÃO}

O amicus curiae é um instituto bastante curioso, inclusive quanto a sua própria criação, pois para alguns remonta do direito romano, para outros do direito inglês, sendo utilizados desde o século XVII, passando a ser destacado no direito norte-americano.

O "amigo da Corte" deve intervir no processo para trazer um maior contingente de informação para o Julgador, com o objetivo de fornecer dados que auxiliem na busca da Verdade Real e, consequentemente, de se garantir ao Julgador que se valha de um processo justo.

Assim para conseguirmos debater se essas premissas são verdadeiras, trataremos primeiramente de uma rápida visão do instituto da amicus curiae, com a intenção de conceitua-lo, bem como, de demonstrar seu histórico no direito brasileiro.

Em seguida trataremos do princípio processual constitucional do devido processo legal. Aqui estudaremos a divisão do devido processo legal em substantivo e processual, o histórico e a importância do tema.

Passaremos, para uma analise da amicus curiae no direito brasileiro e posteriormente a problematização que verificamos nos casos em que se tem requerido a intervenção no ordenamento pátrio.

Em seguida apresentaremos nosso entendimento neste singelo compêndio com a apresentação da conclusão.

\section{AMICUS CURIAE}

Neste trabalho buscaremos estudar esse instituto inserido em nosso ordenamento jurídico como intervenção de terceiros, a partir da Lei n. 15.105 de março de 2015, mas que já encontrava recepção, ainda que não expressamente, na Lei n. 9.494 de 1999, que inseriu o terceiro parágrafo ao artigo 482 do Código de Processo Civil.

É certo que, antes disso já havíamos tido o aparecimento desse instituto ainda de maneira informal, como vemos na Ementa que teve como relator o Ministro Celso de Mello, na ADI $798^{1}$, julgado datado de $1^{\circ}$ de agosto de 1994 , portanto antes mesmo de legislação sobre o tema.

${ }^{1}$ E M E N T A: AÇÃO DIRETA DE INCONSTITUCIONALIDADE - INTERVENÇÃO ASSISTENCIAL - IMPOSSIBILIDADE - ATO JUDICIAL QUE DETERMINA A JUNTADA, POR LINHA, DE PECAS DOCUMENTAIS - DESPACHO DE MERO EXPEDIENTE - IRRECORRIBILIDADE - AGRAVO REGIMENTAL NÃO CONHECIDO. 
Notemos que, no caso acima, se falou em assistência litisconsorcial, não aceita em ação de inconstitucionalidade, mas admitiram a juntada de documentos por um terceiro não revestido de qualquer denominação nos autos.

Neste sentido, o entendimento de Cassio Scarpinella, nos parece interessante, ao asseverar:

“Já escrevemos no início do item 1 que existem poucas manifestações da nossa doutrina e da nossa jurisprudência específica ou exclusivamente sobre o amicus curiae. E estas poucas buscam enfrentar o tema, em grande proporção, a partir do instituto da intervenção de terceiros. Em geral, os autores concluem que o amicus curiae é uma forma anômala, sui generis, de intervenção de terceiros, ou, em sentido diametralmente oposto, mercê do grande número de suas diferenças com as tradicionais hipóteses que conhecemos de intervenção de terceiro no processo civil, ainda que diferenciada dos demais casos. Em menor escala, há manifestações em que o estudo do amicus curiae é feito a partir de distinções ou aproximações com outros sujeitos processuais.” (Sacarpinella: 2012. p.372)

\section{Conceito}

O instituto da amicus curiae traduzido como "amigo da corte", consiste naquele que intervirá no processo com o objetivo de ajudar o Juízo, sendo, pois um garantidor da cooperação judicial.

Segundo Pedro Lenza

- O processo de controle normativo abstrato instaurado perante o Supremo Tribunal Federal não admite a intervenção assistencial de terceiros. Precedentes. Simples juntada, por linha, de pecas documentais apresentadas por órgão estatal que, sem integrar a relação processual, agiu, em sede de ação direta de inconstitucionalidade, como colaborador informal da Corte (amicus curiae): situação que não configura, tecnicamente, hipótese de intervenção ad coadjuvandum. - Os despachos de mero expediente - como aqueles que ordenam juntada, por linha, de simples memorial expositivo -, por não se revestirem de qualquer conteúdo decisório, não são passiveis de impugnação mediante agravo regimental (CPC, art. 504).

(ADI 748 AgR, Relator(a): Min. CELSO DE MELLO, Tribunal Pleno, julgado em 01/08/1994, DJ 18-11-1994 PP-31392 EMENT VOL-01767-01 PP-00010) 
"o objetivo do instituto amicus curiae é auxiliar a instrução processual, portanto, o autor entende possível a sua admissão no processo até o inicio do julgamento. Uma vez em curso e já iniciado o julgamento, a presença do amicus curiae deverá ser rejeitada para evitar tumulto processual" (LENZA; Pedro, 2008, p. 191)

Assim podemos dizer que o amicus curiae seria um colaborador informal da corte, que não poderá ser considerado como um terceiro interveniente, ou um assistente na demanda.

Ora, claro está que o amigo será da corte, sendo, portanto equidistante das partes, daí se apresentar alguns órgãos com essa função inerente, como a Comissão de Valores Mobiliário, o CADE; a Ordem dos Advogados do Brasil, dentre outros.

\section{DEVIDO PROCESSO LEGAL}

Nosso direito, quanto positivado, busca seu embasamento na norma, que, como sabemos, não consegue regular todos os caso, dai, se buscar a "completude" trazida por Bobbio para sanar as "lacunas". (Bobbio: 1982. p.115)

Para se obter um ordenamento completo utilizamos o procedimento da auto-integração, ou seja, utilizaremos os princípio gerais do direito que completarão o ordenamento jurídico.

Para Bobbio

"A expressão "princípios gerais do direito" foi usada pelo legislador de 1865, mas pelos equívocos que podia suscitar, quanto a se se deveria entender por "Direito" o Direito natural ou o Direito positivo, o projeto do novo código havia adotado a fórmula "princípios gerais do Direito vigente", modificada na última redação para a atual fórmula: "princípios gerais do ordenamento jurídico do Estado". (Bobbio: 1982. p.157)

E continua:

“Os princípios gerais são apenas, a meu ver, normas tanto que é velha questão entre os juristas se os princípios são normas. Para mim não há dúvida: os princípios gerais são normas. 
Ora essa normatização principiológica norteia o processo, quer com princípios constitucionais, quer com princípios de natureza infraconstitucionais.

Para este estudo trataremos especificamente do princípio do devido processo legal, considerado "o princípio dos princípios" sendo os demais (contraditório, ampla defesa, direito de ação, isonomia, dentre outros), a ele relacionados.

“O princípio (do devido processo legal) é tão amplo e tão significativo que legitima a jurisdição e se confunde com o próprio Estado de Direito. Assim, aplica-se tanto na jurisdição civil e na penal como nos procedimentos administrativos. Ademais, engloba a reivindicação de direitos (inclusive de declarar a inconstitucionalidade de lei), a eficaz defesa e a produção de provas. No devido processo legal estão enfeixadas garantias representadas principalmente pelos princípios do contraditório, ampla defesa, duplo grau, publicidade, juiz natural, assist ncia judiciária gratuita” (...) “Com estas características, o princípio do devido processo justifica-se como verdadeiro princípio informativo de todos os princípios ligados ao processo e ao procedimento.” (Portanova: 1997. p. 146)

\section{Conceito}

O devido processo legal pode ser considerado como o princípio que garante ao jurisdicionado um processo justo, dai, correlacionarmos ao princípio inicial da Constituição Pátria, ou seja, o princípio da dignidade da pessoa humana ${ }^{2}$. Isso porque em um estado democrático de direito, qualquer jurisdicionado deve ter um processo, para somente então ser, quando for o caso, punido ou ainda privado de seus bens.

\section{${ }^{2}$ Art. $1^{\circ}$ A República Federativa do Brasil, formada pela união indissolúvel dos Estados e Municípios e do Distrito Federal, constitui-se em Estado Democrático de Direito e tem como fundamentos:}

I - a soberania;

II - a cidadania

III - a dignidade da pessoa humana;

IV - os valores sociais do trabalho e da livre iniciativa;

V - o pluralismo político.

Parágrafo único. (grifo nosso) 
É a garantia ao trinômio que norteia o due processo of law, ou seja, a vida-liberdadepropriedade.

Sobre o princípio o Professor Nelson Nery assevera:

"O princípio constitucional fundamental do processo civil, que entendemos como a base sobre a qual os outros princípios e regras se sustentam, é o devido processo legal, expressão oriunda da inglesa due processo of law para que daí decorressem todas as consequências processuais que garantiam aos litigantes o direito a um processo e a uma sentença justa. É, por assim dizer, o gênero do qual todos os demais princípios e regras constitucionais são espécies. (Nelson Nery: 2013)

O devido processo legal para Rogério Lauria Tucci proclama o Estado de Direito para:

“a) elaboração regular e dorreta da lei, bem como sua razoabilidade, senso de justiça e enquadramento nas preceituações constitucionais (substantive due processo $f$ law, segundo o desdobramento da concepção norteamericana);

b) aplicação judicial das normas jurídicas (não só da lei, como tal própria e estritamente concebida, mas por igual, de toda e qualquer expressão do direito), através de instrumento hábil à sua interpretação e realização, que é o "processo" (judicial process); e

c) asseguração, neste, de paridade de armas as partes, visando à igualdade substancial. (Lauria Tucci: 1993, p:

Assim temos que o devido processo legal, de forma genérica se norteia, como já dissemos, no trinômio vida, liberdade e propriedade. Porém ele, não pode ser visto exclusivamente neste princípio procedimental ou adjetivo, devemos vê-lo, também, no sentido material ou substantivo.

\section{Devido processo legal substantivo.}

Segundo a doutrina devemos observar o devido processo legal substantivo ou material no sentido de que se deve observar direitos das pessoas à vida, a liberdade, poderíamos dizer que seria a observância da dignidade da pessoa humana. Ou nos dizeres de J.J. GOMES CANOTILHO 
“ $\mathrm{s}$ autoridades legiferantes deve ser vedado o direito de disporem arbitrariamente da vida, da liberdade e da propriedade das pessoas, isto é, sem razões materialmente fundadas para o fazerem" (Canotilho: 2003, p. 494).

A existência do devido processo legal substantivo ou material está presente na jurisprudência, como no HC 107082 / RS - RIO GRANDE DO SUL, onde o Ministro Ayres Britto, relator do habeas corpus, em julgamento datado de 27 de março de 2012, asseverou na ementa:

HABEAS CORPUS. CRIME DE TENTATIVA DE FURTO AGRAVADO. PACIENTE REINCIDENTE ESPECÍFICO. DIRETIVAS DE APLICAÇÃO DO PRINCÍPIO DA INSIGNIFICÂNCIA. JUSTIÇA MATERIAL. PONDERABILIDADE NO JUÍZO DE ADEQUAÇÃO TÍPICA DE CONDUTAS FORMALMENTE CRIMINOSAS. SIGNIFICÂNCIA PENAL. CONCEITO CONSTITUCIONAL. ORDEM DENEGADA.

1. A norma legal que descreve o delito e comina a respectiva pena atua por modo necessariamente binário, no sentido de que, se, por um lado, consubstancia o poder estatal de interferência na liberdade individual, também se traduz na garantia de que os eventuais arroubos legislativos de irrazoabilidade e desproporcionalidade se expõem a controle jurisdicional. Donde a política criminal-legislativa do Estado sempre comportar mediação judicial, inclusive quanto ao chamado "crime de bagatela" ou "postulado da insignificância penal" da conduta desse ou daquele agente. Com o que o tema da significância penal confirma que o "devido processo legal" a que se reporta a Constituição Federal no inciso LIII do art. $5^{\circ}$ é de ser interpretado como um devido processo legal substantivo ou material. Não meramente formal.

2. A insignificância penal expressa um necessário juízo de razoabilidade e proporcionalidade de condutas que, embora formalmente encaixadas no molde legal-punitivo, substancialmente escapam desse encaixe. E escapam desse molde simplesmente formal, como exigência mesma da 
própria justiça material enquanto valor ou bem coletivo que a nossa Constituição Federal prestigia desde o seu principiológico preâmbulo. Justiça como valor, a se concretizar mediante uma certa dosagem de razoabilidade e proporcionalidade na concretização dos valores da liberdade, igualdade, segurança, bem-estar, desenvolvimento, etc. Com o que ela, justiça, somente se realiza na medida em que os outros valores positivos se realizem por um modo peculiarmente razoável e proporcional.

3. A justiça não tem como se incorporar, sozinha, à concreta situação das protagonizações humanas, exatamente por ser ela a própria resultante de uma certa cota de razoabilidade e proporcionalidade na historicização de valores positivos (os mencionados princípios da liberdade, da igualdade, da segurança, do bem-estar, do desenvolvimento, etc.). Daí que falar do valor da justiça é falar dos outros valores que dela venham a se impregnar por se dotarem de um certo quantum de ponderabilidade, se por este último termo (ponderabilidade) englobarmos a razoabilidade e a proporcionalidade no seu processo de concreta incidência. Assim como falar dos outros valores é reconhecê-los como justos na medida em que permeados desse efetivo quantum de ponderabilidade (mescla de razoabilidade e proporcionalidade, torna-se a dizer). Tudo enlaçado por um modo sinérgico, no sentido de que o juízo de ponderabilidade implica o mais harmonioso emprego do pensamento e do sentimento do julgador na avaliação da conduta do agente em face do seu subjetivado histórico de vida e da objetividade da sua concreta conduta alegadamente delitiva. 4. É possível extrair do ordenamento jurídico brasileiro a premissa de que toda conduta penalmente típica só é penalmente típica porque significante, de alguma forma, para a sociedade e para a própria vítima. Em tema de política criminal, a 
Constituição Federal pressupõe lesão significante a interesses e valores (os chamados “bens jurídicos”) por ela avaliados como dignos de proteção normativa.

5. Ao prever, por exemplo, a categoria de infrações de menor potencial ofensivo (inciso I do art. 98), a Constituição Federal logicamente nega a significância penal de tudo que ficar aquém desse potencial, de logo rotulado de "menor"; ou seja, quando a Constituição Federal concebe a categoria das infrações de menor potencial ofensivo, parece mesmo que o faz na perspectiva de uma conduta atenuadamente danosa para a vítima e a sociedade, é certo, mas ainda assim em grau suficiente de lesividade para justificar uma reação estatal punitiva. Pelo que estabelece um vínculo operacional direto entre o efetivo dano ao bem jurídico tutelado, por menor que seja, e a necessidade de uma resposta punitiva do Estado.

6. A contrario sensu, o dano que subjaz à categoria da insignificância penal não caracteriza, materialmente, sequer lesão de pequena monta; ou seja, trata-se de ofensividade factualmente nula, porquanto abaixo até mesmo da concepção constitucional de dano menor. Donde sua categorização como penalmente atípica.

7. É possível listar diretrizes de aplicação do princípio da insignificância, a saber: a) da perspectiva do agente, a conduta, além de revelar uma extrema carência material, ocorre numa concreta ambiência de vulnerabilidade social do suposto autor do fato; b) do ângulo da vítima, o exame da relevância ou irrelevância penal deve atentar para o seu peculiarmente reduzido sentimento de perda por efeito da conduta do agente, a ponto de não experimentar revoltante sensação de impunidade ante a não-incidência da norma penal que, a princípio, lhe favorecia; c) quanto aos meios e modos de realização da conduta, não se pode reconhecer como irrelevante a ação que se manifesta mediante o emprego de violência ou ameaça à integridade física, ou moral, tanto da vítima quanto de terceiros. Reversamente, 
sinaliza infração de bagatela ou penalmente insignificante aquela que, além de não se fazer acompanhar do modus procedendi que estamos a denunciar como intolerável, revela um atabalhoamento ou amadorismo tal na sua execução que antecipa a sua própria frustração; isto é, já antecipa a sua marcante propensão para a forma não mais que tentada de infração penal, porque, no fundo, ditadas por um impulso tão episódico quanto revelador de extrema carência econômica; d) desnecessidade do poder punitivo do Estado, traduzida nas situações em que a imposição de uma pena se auto-evidencie como tão despropositada que até mesmo a pena mínima de privação liberdade, ou sua conversão em restritiva de direitos, já significa um desbordamento de qualquer idéia de proporcionalidade; e) finalmente, o objeto material dos delitos patrimoniais há de exibir algum conteúdo econômico, seja para efetivamente desfalcar ou reduzir o patrimônio da vítima, seja para ampliar o acervo de bens do agente. 8. No caso, o paciente é reincidente específico quanto ao crime de furto. Pelo que a tentativa de furto agravado de bens avaliados em $\mathrm{R} \$ 180,00$ (cento e oitenta reais), mediante a invasão de uma empresa, não se amolda à ponderabilidade de todas as diretivas acima listadas. 9. Habeas corpus denegado.

(HC 107082, Relator(a): Min. AYRES BRITTO, Segunda Turma, julgado em 27/03/2012, PROCESSO ELETRÔNICO DJe-081 DIVULG 25-04-2012 PUBLIC 26-04-2012)

\section{Devido processo legal procedimental.}

Aqui o que devemos observar é o direito da pessoa ao um processo justo. Ou nos dizeres de Canotilho:

"A ideia de um due process jurisdicional que, como se viu, esteve na origem da sedimentação da justiça processual e procedimental, é hoje agitada a propósito da 
conformação justa e adequada do direito à tutela jurisdicional. Como prescreve agora (depois da revisão de 1997) o art. $20^{\circ} / 3$ da CRP, "todos $t \mathrm{~m}$ direito a que uma casa em que intervenham seja objecto da decisão em prazo razoável e mediante processo equitativo"." (Canotilho: 2004. p.483)

Ora o devido processo legal busca um processo intermediado por todos os princípios processuais constitucionais, ou seja, com igualdade, com contraditório, com razoável duração. Para garantir esses direitos fundamentais do processo o mesmo obedecerá às normas inseridas na normatização da legislação processual.

\section{Histórico do devido processo legal}

O devido processo legal passou a ser visto no ordenamento primeiramente na Magna Carta Liberttun $^{3}$, do rei inglês João Sem Terra, onde se estabeleceu o direito a um processo antes de qualquer punição.

Após essa primeira previsão, o devido processo legal passou a ser repetido em diversos ordenamentos, sendo como ponto marcante a Constituição dos Estados Unidos Americanos que asseverou:

V - "No person shall be held to answer for a capital, or otherwise infamous crime, unless on a presentment or indictment of a Grand Jury, except in cases arising in the land or naval forces, or in the Militia, when in actual service in time of War or public danger; nor shall any person be subject for the same offense to be twice put in jeopardy of life or limb; nor shall be compelled in any criminal case to be a witness against himself, nor be deprived of life, liberty, or property, without due process of law; nor shall private property be taken for public use, without just compensation".

XIV - "Section 1. All persons born or naturalized in the United States, and subject to the jurisdiction thereof, are 
citizens of the United States and of the State wherein they reside. No State shall make or enforce any law which shall abridge the privileges or immunities of citizens of the United States; nor shall any State deprive any person of life, liberty, or property, without due process of law; nor deny to any person within its jurisdiction the equal protection of the laws..." 4

${ }^{3}$ Nenhum homem livre será detido ou sujeito à prisão, ou privado dos seus bens, ou colocado fora da lei, ou exilado, ou de qualquer modo molestado, e nós não procederemos nem mandaremos proceder contra ele senão mediante um julgamento regular pelos seus pares ou de harmonia com a lei do país. (Carta Liberttun in http://www.direitoshumanos.usp.br/index.php/Documentos-anteriores-à-criação-da-

Sociedade-das-Nações-até-1919/magna-carta-1215-magna-charta-libertatum.html, acessado em 18 de dezembro de 2015 às 10:45 hs)

${ }^{4} \mathrm{~V}$ - "ninguém será detido para responder por crime capital, ou outro crime infamante, salvo O devido processo legal também é referendado no direito espanhol, onde a Constituição Espanhola de 27 de dezembro de 1978, em seu artigo 24.1, afirma que:

"Todas las personas tienen derecho a obtener la tutela efectiva de los jueces y tribunales en el ejercicio de sus derechos e intereses legítimos" 5

e complementando, o artigo 24.2. diz:

"Asimismo, todos tienen derecho al juez ordinario predeterminado por la ley, a la defensa y a la asistencia de letrado, a ser informados de la acusación formulada contra ellos, a un proceso público sin dilaciones indebidas y con todas las garantías"

$\mathrm{Na}$ Latinoamerica merece destaque o due process of law (devido processo legal) constante na Convenção Americana de Direitos Humanos, também conhecida como Pacto de San Jose, que ocorreu em 1968, na cidade da Costa Rica, que em seu artigo 8.1 que prevê:

Artigo 8. Garantias judiciais

1. Toda pessoa tem direito a ser ouvida, com as devidas garantias e dentro de um prazo razoável, por um juiz ou

em uma denúncia ou acusação perante um grande júri, exceto nos casos decorrentes da terra ou de forças naval, ou na milícia, durante serviço real, em tempo de guerra ou de perigo público; nem qualquer pessoa sujeita para o mesmo crime se duas vezes colocar em perigo a 
vida ou integridade; nem deve ser compelida em qualquer caso criminal a ser testemunha contra si mesmo, nem ser privado da vida, liberdade ou propriedade, sem o devido processo legal; nem propriedade privada poderá ser expropriada para uso público, sem uma compensação justa".

XIV - "seção 1. Todas as pessoas nascida ou naturalizada nos Estados Unidos e sujeitas à jurisdição, são cidadãos dos Estados Unidos e do estado em que residem. Nenhum Estado deve fazer ou cumprir qualquer lei que serão abreviarão os privilégios ou imunidades dos cidadãos dos Estados Unidos; nem qualquer Estado privará qualquer pessoa da vida, liberdade ou propriedade, sem o devido processo legal. (tradução livre)

5 "Todo mundo tem o direito de obter a proteção efetiva dos juízes e tribunais no exercício dos seus direitos e interesses legítimos" (tradução livre)

6 "Igualmente, todo mundo tem direito ao juiz ordinário predeterminado pela lei, à defesa e à assistência de um advogado, para ser informado sobre a acusação contra eles, de um processo público, sem demora e com todas as garantias." (tradução livre)

tribunal competente, independente e imparcial, estabelecido anteriormente por lei, na apuração de qualquer acusação penal formulada contra ela, ou para que se determinem seus direitos ou obrigações de natureza civil, trabalhista, fiscal ou de qualquer outra natureza.

No Brasil o devido processo legal obtém a peje de princípio processual constitucional a partir da Constituição de 1988, que inseriu no artigo 5, inciso $\operatorname{LIV}^{7}$ o devido processo legal.

Assim passamos a garantir o estado democrático de direito, onde qualquer punição obedecerá a todos os outros princípios que norteiam o processo.

\section{Importância do princípio.}

Pela mera leitura dos textos legais, podemos verificar que o devido processo legal garante não somente um processo, mas que o mesmo deva ser justo, em tempo razoável, com observância do contraditório, da ampla defesa e, até mesmo da publicidade.

Como já dissemos esse princípio assegura a própria dignidade da pessoa humana, que em qualquer circunstância terá direito ao provimento jurisdicional para ser privado de sua liberdade ou de seu patrimônio.

É a já mencionada trilogia do devido processo legal, isto é, vida - liberdade - propriedade, parâmetros essenciais de qualquer sociedade.

Assim asseguramos ao jurisdicionado um processo justo, com cumprimento de todas as normas procedimentais, onde se prevê que da decisão monocrática poderá a parte que se sentir lesada, recorrer à instância superior. 


\section{A AMICUS CURIAE - EXPERIÊNCIA PÁTRIA.}

No direito brasileiro, se tratarmos de legislação vigente, a amicus curiae encontrará previsão expressa apenas no artigo 23, 1o, da Resolução n. 390/200 do Conselho da ustiça ederal.

${ }^{7}$ Art. $5^{\circ}$ Todos são iguais perante a lei, sem distinção de qualquer natureza, garantindo-se aos brasileiros e aos estrangeiros residentes no País a inviolabilidade do direito à vida, à liberdade, à igualdade, à segurança e à propriedade, nos termos seguintes:

LIV - ninguém será privado da liberdade ou de seus bens sem o devido processo legal;

Claro que, no Novo Código de Processo Civil, o amicus curiae foi inserido como no Título III, denominado de intervenção de terceiros.

Assim o artigo 138 do NCPC diz:

Art. 138. O juiz ou o relator, considerando a relevância da matéria, a especificidade do tema objeto da demanda ou a repercussão social da controvérsia, poderá, por decisão irrecorrível, de ofício ou a requerimento das partes ou de quem pretenda manifestar-se, solicitar ou admitir a participação de pessoa natural ou jurídica, órgão ou entidade especializada, com representatividade adequada, no prazo de 15 (quinze) dias de sua intimação.

$\S 1^{\underline{0}}$ A intervenção de que trata o caput não implica alteração de competência nem autoriza a interposição de recursos, ressalvadas a oposição de embargos de declaração e a hipótese do $\S 3^{\underline{0}}$.

$\S 2^{0}$ Caberá ao juiz ou ao relator, na decisão que solicitar ou admitir a intervenção, definir os poderes do amicus curiae.

$\S 3^{\circ} \mathrm{O}$ amicus curiae pode recorrer da decisão que julgar o incidente de resolução de demandas repetitivas.

Vemos que a idéia do amicus curiae quando vista em termos práticos, ou seja, nos caso apresentados pelo Supremo Tribunal ederal, não vemos o "amigo da corte" mas o amigo da parte, alguém interessado no conflito, querendo intervir para formar a convicção do julgador para os seus interesses.

Difere da analogia que se atribuía ao amicus curiae com a figura do Ministério Público 
quanto fiscal da lei, onde a função é garantir o cumprimento da Lei, sem pender a qualquer das partes litigantes.

Tal fato não ocorre, como veremos abaixo, pelos casos exemplificativos buscado.

\section{Distorção do instituto no ordenamento brasileiro}

No Supremo Tribunal Federal a primeira menção do amicus curiae se da em uma ação declaratória de inconstitucionalidade, onde a aceitação da apresentação de documentos pela Assembleia Legislativa do Rio Grande do Sul, que não era parte no processo, gerou o Agravo Regimental, que teve como relator o Ministro CELSO DE MELLO, julgado em 01/08/1994. (ADI 748 AgR, Relator(a): Min. CELSO DE MELLO, Tribunal Pleno, julgado em 01/08/1994, DJ 1811-1994 PP-31392 EMENT VOL-01767-01 PP-00010) ${ }^{8}$

É verdade que, ainda que não tenha atuado como coadjuvante na demanda, os documentos juntados, não eram apenas para trazer informações a Corte, mas buscavam formar a convicção dos julgadores para benefício de uma das partes, portanto, parece-nos que aqui a intervenção não era em benefício da Justiça mas de uma das partes.

Neste mesmo sentido vamos ter outras inúmeras intervenções de "amigos da Corte" que pretendem que a decisão seja a favor de um das partes, desvirtuando a ideia da cooperação à Justiça, neste sentido, temos a inclusão de diversas entidades na ação de descumprimento de preceito fundamental de número 54 ajuizada pela CONFEDERAÇÃO NACIONAL DOS TRABALHADORES NA SAÚDE - CNTS, tendo intervindo como amicus curiae ANIS nstituto de Biotécnica, Direitos umanos e nero.

Sem desconsiderarmos que na primeira tentativa de intervenção, admitiu-se a juntada de documentos, sem todavia denominar o interveniente, inclusive tendo-se inicialmente cogitado que o mesmo não poderia ser considerado um assistente litisconsorcial, ou seja, alguém com interesse jurídico na demanda, o que não é admitido na ideia conceitual do "amigo da corte", cujo interesse é meramente a Justiça, ou seja, um processo devido, justo.

Foi indeferido o pedido da

- CNBB como amicus curiae, por entender não ser cabível a intervenção de terceiro. ${ }^{9}$

${ }^{8}$ E M E N T A: AÇÃO DIRETA DE INCONSTITUCIONALIDADE - INTERVENÇÃO ASSISTENCIAL - IMPOSSIBILIDADE - ATO JUDICIAL QUE DETERMINA A JUNTADA, POR LINHA, DE PECAS DOCUMENTAIS - DESPACHO DE MERO EXPEDIENTE - IRRECORRIBILIDADE - AGRAVO REGIMENTAL NÃO CONHECIDO. - O processo de controle normativo abstrato instaurado perante o Supremo Tribunal Federal não admite a intervenção assistencial de terceiros. Precedentes. Simples juntada, por linha, de pecas documentais apresentadas por órgão estatal que, sem integrar a relação processual, agiu, 
em sede de ação direta de inconstitucionalidade, como colaborador informal da Corte (amicus curiae): situação que não configura, tecnicamente, hipótese de intervenção ad coadjuvandum. - Os despachos de mero expediente - como aqueles que ordenam juntada, por linha, de simples memorial expositivo -, por não se revestirem de qualquer conteúdo decisório, não são passiveis de impugnação mediante agravo regimental (CPC, art. 504).

${ }^{9}$ No mesmo 17 de junho, prolatei a seguinte decisão:

\section{A O DE DESC PR ENTO DE PRECE TO NDA ENTAL - NTER EN O} DE TERCEIRO - REQUERIMENTO - IMPROPRIEDADE.

1. Eis as informações prestadas pela Assessoria:

Em outro julgado o pedido para intervenção como amicus curiae, foi negado por estar a ação declaratória de inconstitucionalidade já estar na fase decisória ${ }^{10}$.

\section{CONCLUSÃO}

No estudo pretendido observamos uma aplicação equivocada do instituto do amicus curiae, pois se o que se pretende é a admissão de um terceiro que venha a contribuir a formação da convicção do julgador, ou seja, o instituto do "amigo da Corte" seria o assecuratório do principio do devido processo legal, ou seja, um processo justo, onde asseguramos igualdade entre as partes, para que possam apresentar os fatos que formaram a convicção do julgador, que estará fazendo a Justiça.

Desta maneira, não podemos aceitar que a Corte limite a intervenção do "Amigo" a um momento processual instrutório, por exemplo, pois a sua intervenção não seria para ajudar as partes, mas sim o próprio Juízo.

Infelizmente não estamos vendo, a princípio, o amicus curiae como um terceiro independente da parte, mas em geral, um terceiro interveniente com interesse em um dos polos da demanda. Bibliografia

A Confer ncia Nacional dos Bispos do Brasil - CNBB - requer a intervenção no processo em refer ncia, como amicus curiae, conforme preconiza o 1o do artigo o da Lei 9.882/1999, e a juntada de procuração. Pede vista pelo prazo de cinco dias.

2. O pedido não se enquadra no texto legal evocado pela requerente. Seria dado versar sobre a aplicação, por analogia, da Lei no 9.8 8/99, que disciplina também processo objetivo - ação direta de inconstitucionalidade e ação declaratória de constitucionalidade. Todavia, a admissão de terceiros não implica o reconhecimento de direito subjetivo a tanto. ica a critério do relator, caso entenda oportuno. Eis a intelig ncia do artigo 7o, 2o, da Lei no $9.88 / 99$, sob pena de tumulto processual. Tanto é assim que o ato do relator, situado no campo da prática de ofício, não é suscetível de impugnação na via recursal.

3. Indefiro o pedido.

4. Publique-se.

(ADPF 54, Relator(a): Min. MARCO AURÉLIO, Tribunal Pleno, julgado em 12/04/2012, 
ACÓRDÃO ELETRÔNICO DJe-080 DIVULG 29-04-2013 PUBLIC 30-04-2013)

10 EMENTA: PROCESSSUAL CIVIL. AGRAVO REGIMENTAL. CONTROLE DE CONSTITUCIONALIDADE CONCENTRADO. ADMISSÃO DE AMICUS CURIAE. PRAZO. Segundo precedente da Corte, é extemporâneo o pedido para admissão nos autos na qualidade de amicus curiae formulado após a liberação da ação direta de inconstitucionalidade para julgamento. Agravo regimental ao qual se nega provimento.

(ADI 4067 AgR, Relator(a): Min. JOAQUIM BARBOSA, Tribunal Pleno, julgado em 10/03/2010, DJe-071 DIVULG 22-04-2010 PUBLIC 23-04-2010 EMENT VOL-02398-01 PP-00060 RDECTRAB v. 17, n. 190, 2010, p. 111-113)

BOBBIO, Norberto. Teoria do ordenamento jurídico. Brasília: Editora da Universidade de Brasília. 10ª . Edição. 1982.

-----. O positivismo jurídico - lições de filosofia do direito. São Paulo, SP, Icone Editora. 2006.

CABRAL, Antônio do Passo. Pelas asas de Hermes: A intervenção do amicus curiae, um terceiro especial. Uma análise dos institutos interventivos similares - $O$ amicus e o Vertreter des Öffentlichen interesses. Revista de Processo 117/12, São Paulo, Revista dos Tribunais, set.-out., 2004.

CARNEIRO, Athos Gusmão. Intervenção de Terceiros, São Paulo, São Paulo, Saraiva, 2001.

CANOTILHO, J. J. Gomes. Direito Constitucional e Teoria da Constituição, 4. a ed., Coimbra, Almedina, 2000.

FERRAZ, Anna Candida Cunha. O amicus curiae e a democratizaçãoo e a legitimação da jurisdição constitucional concentrada. Revista Mestrado em Direito Osasco, Ano 8, n.1, 2008, p. $53-72$

FISS, Owen. Um novo processo civil, São Paulo, SP, Editora Revista dos Tribunais, 2004. Livraria Lider, 2004.

GOLDSCHMIDT, James. Princípios gerais do processo civil (Teoria geral do processo), Belo Horizonte, Minas Gerais 
GRINOVER, Ada Pellegrini. As garantias constitucionais do direito de ação, São Paulo, SP, Editora Revista dos Tribunais, 1973.

---. O princípio do juiz natural e sua dupla garantia. Revista de Processo 29/11, São Paulo, SP, Revista dos Tribunais, jan-mar, 1983.

HABERLE, Peter. Hermenêutica Constitucional: a sociedade aberta dos Interpretes da Constituição: contribuição para a interpretação pluralista e "procedimental" da Constituição.

Trad. Gilmar Ferreira Mendes. Porto Alegre, Safe, 2002.

KOHLER, Ricardo Carlos. «Amicus Curiae »: amigos del tribunal. Astrea, Buenos Aires, 2010.

LENZA, Pedro. Direito Constitucional esquematizado. 12ª edição. São Paulo: Saraiva, 2008.

LIEBMAN, Enrico Tullio. Do arbítrio à razão reflexões sobre a motivação da sentença.

Revista de Processo, n. ${ }^{\circ}$ 29/79, São Paulo: Revista dos Tribunais, jan./mar. 1983.

NERY JR, Nelson. Princípios do processo na Constituição Federal. 2ª . Edição E-book baseada na $11^{\text {a }}$. Impressa. São Paulo, SP: Editora Revista dos Tribunais

PORTANOVA, Rui. Princípios do processo civil. $2^{\mathrm{a}}$ Tiragem. Porto Alegre: Livraria do advogado. 1997.

SCARPINELLA Bueno, Cassio. Amicus curiae no processo civil brasileiro: um terceiro enigmático. $3^{\text {a }}$ Edição. São Paulo : Saraiva, 2012.

.....Quatro perguntas e quatro respostas sobre o Amicus Curiae. Revista Nacional da agistratura. Ano, n. 5. Brasília: Escola Nacional da agistratura/Associação dos agistrados Brasileiros, maio de 2008, páginas 132-138. 
TUCCI, Rogério Lauria e TUCCI, José Rogério Cruz. Devido processo legal e tutela jurisdicional. São Paulo, SP: Editora Revista dos Tribunais. 1993 
